\title{
Increase in Tuberculosis Diagnostic Delay during First Wave of the COVID-19 Pandemic: Data from an Italian Infectious Disease Referral Hospital
}

\author{
Francesco Di Gennaro ${ }^{1, *} \mathbb{B}$, Gina Gualano ${ }^{1}$, Laura Timelli ${ }^{1}$, Pietro Vittozzi ${ }^{1}$, Virginia Di Bari ${ }^{1}$, \\ Raffaella Libertone ${ }^{1}$, Carlotta Cerva ${ }^{1}{ }^{1}$, Luigi Pinnarelli ${ }^{2}$, Carla Nisii ${ }^{1}$, Stefania Ianniello ${ }^{1}$, Silvia Mosti ${ }^{1}$, \\ Nazario Bevilacqua ${ }^{1}$, Fabio Iacomi ${ }^{1}$, Annalisa Mondi ${ }^{1}$, Simone Topino ${ }^{1}$, Delia Goletti ${ }^{1}{ }^{1}$, Francesco Vaia ${ }^{1}$, \\ Giuseppe Ippolito ${ }^{1} \mathbb{D}$, Enrico Girardi ${ }^{1}$ and Fabrizio Palmieri ${ }^{1} @$ on behalf of the TB-INMI Working Group ${ }^{\dagger}$
}

check for updates

Citation: Di Gennaro, F.; Gualano, G.; Timelli, L.; Vittozzi, P.; Di Bari, V.; Libertone, R.; Cerva, C.; Pinnarelli, L.; Nisii, C.; Ianniello, S.; et al. Increase in Tuberculosis Diagnostic Delay during First Wave of the COVID-19 Pandemic: Data from an Italian Infectious Disease Referral Hospital. Antibiotics 2021, 10, 272. https:// doi.org/10.3390/antibiotics10030272

Academic Editor: Danila V. Zimenkov

Received: 5 February 2021

Accepted: 6 March 2021

Published: 8 March 2021

Publisher's Note: MDPI stays neutral with regard to jurisdictional claims in published maps and institutional affiliations.

Copyright: (c) 2021 by the authors Licensee MDPI, Basel, Switzerland. This article is an open access article distributed under the terms and conditions of the Creative Commons Attribution (CC BY) license (https:// creativecommons.org/licenses/by/ $4.0 /)$.
1 National Institute for Infectious Diseases “L. Spallanzani” IRCCS, 00161 Rome, Italy; gina.gualano@inmi.it (G.G.); laura.timelli@inmi.it (L.T.); pietro.vittozzi@inmi.it (P.V.); virginia.dibari@inmi.it (V.D.B.); Raffaella.libertone@inmi.it (R.L.); Carlotta.cerva@inmi.it (C.C.); carla.nisii@inmi.it (C.N.); stefania.ianniello@inmi.it (S.I.); silvia.mosti@inmi.it (S.M.); nazario.bevilacqua@inmi.it (N.B.); Fabio.iacomi@inmi.it (F.I.); annalisa.mondi@inmi.it (A.M.); simone.topino@inmi.it (S.T.); delia.goletti@inmi.it (D.G.); Francesco.vaia@inmi.it (F.V.); giuseppe.ippolito@inmi.it (G.I.); enrico.girardi@inmi.it (E.G.); fabrizio.palmieri@inmi.it (F.P.)

2 Department of Epidemiology of Lazio Regional Health Service, 00147 Rome, Italy; 1.pinnarelli@deplazio.it

* Correspondence: francesco.digennaro@inmi.it; Tel.: +39-392-480-4707

† TB-INMI Working Group: Fabrizio Palmieri, Gina Gualano, Andrea Antinori, Nazario Bevilacqua, Maria Capobianchi, Carmine Ciaralli, Gilda Cuzzi, Alessia De Angelis, Antonino Di Caro, Franca Del Nonno, Gianpiero D’Offizi, Emanuela Ercoli, Delia Goletti, Fabio Iacomi, Stefania Ianniello, Giuseppe Ippolito, Luisa Marchioni, Annelisa Mastrobattista, Maria Musso, Paola Mencarini, Annalisa Mondi, Silvia Mosti, Silvia Murachelli, Emanuele Nicastri, Carla Nisii, Carlo Pareo, Antonella Petrecchia, Nicola Petrosillo, Vincenza Puro, Silvia Rosati, Vincenzo Schininà, Paola Scognamiglio, Tommaso Speranza, Simone Topino, Francesco Vaia.

Abstract: Background: The WHO advised that the impact of COVID-19 pandemic on TB services was estimated to be dramatic due to the disruption of TB services. Methods: A retrospective data collection and evaluation was conducted to include all the patients hospitalized for TB at INMI from 9 March to 31 August 2020 (lockdown period and three months thereafter). For the purpose of the study, data from patients hospitalized in the same period of 2019 were also collected. Results: In the period of March-August 2019, 201 patients were hospitalized with a diagnosis of TB, while in the same period of 2020, only 115 patients, with a case reduction of $43 \%$. Patients with weight loss, acute respiratory failure, concurrent extrapulmonary TB, and higher Timika radiographic scores were significantly more frequently hospitalized during 2020 vs. 2019. The median patient delay was 75 days (IQR: 40-100) in 2020 compared to 30 days (IQR: 10-60) in $2019(p<0.01)$. Diagnostic delays in 2020 remain significant in the multiple logistic model (AOR $=6.93,95 \% \mathrm{CI}$ : 3.9-12.3). Conclusions: Our experience suggests that COVID-19 pandemic had an impact on TB patient care in terms of higher diagnostic delay, reduction in hospitalization, and a greater severity of clinical presentations.

Keywords: tuberculosis; diagnostic delay; COVID 19; SARS CoV2; pandemic

\section{Introduction}

COVID-19, as a result of severe acute respiratory syndrome coronavirus 2 (SARSCoV-2) infection, has been the direct cause of hundreds of thousands of deaths in the world [1,2]. The direct and indirect effects of the pandemic, acting through social, economic, environmental and healthcare pathways, can also be countless [2].

During the first wave of the pandemic, most countries from all over the world declared national lockdown as containment and mitigation measure in order to slow down the virus circulation [3]. Prevention and treatment services for noncommunicable diseases (NCDs) 
have been severely disrupted since the COVID-19 pandemic began, according to a WHO survey [4]

In fact, the burden on health services caused by the COVID-19 emergency has led to several changes in the ordinary management of both communicable and non-communicable diseases, following the reduction or suspension of non-urgent outpatient care (for example, blocking of visits and non-urgent surgery) $[5,6]$.

The impact of COVID-19 pandemic on TB services was estimated to be dramatic, especially in countries where healthcare staff involved in TB management have been reassigned to the COVID-19 emergency [6,7]. WHO advised that the disruption of TB services, due to the COVID-19 pandemic, could lead to fewer TB diagnoses, an increase in diagnostic delay, and TB death [8]. However, few data are yet available on what actually happened [9]. Diagnostic delay with more severe clinical presentations, worst outcomes, and lost to follow-up, are only few of the indirect effects of health services disruption expected mainly during the acute phases of the pandemic [10,11]. Italy was the first European country to be affected by COVID-19 and the first to implement a national lockdown measure along with a strong health services reorganization [12]. In fact, between 9 March and 18 May 18 2020, a national containment and mitigation strategy focused on lockdown was implemented to flatten the curve of the COVID-19 pandemic and to reduce the stress on the Italian National Health Service (INHS) [13].

In the same timeframe, INHS was forced to reorganize itself with the conversion of most hospital wards to COVID-19 units, the health workforce was reallocated, and most of the non-urgent services were suspended [14]. In this scenario, most wards and outpatient services for TB of Italian hospital were also interrupted in their routine activities, which is what happened at the National Institute for Infectious Diseases "L.Spallanzani" (INMI) in Rome, an Italian TB referral hospital.

With the purpose to evaluate the potential impact of first wave of COVID-19 pandemic on TB cases, we performed a retrospective, observational cohort analysis of socio-economic aspects, clinical, microbiological, and radiological findings of patients hospitalized for TB at INMI during 2019 and 2020.

\section{Results}

\subsection{Clinical, Microbiological and Radiological Findings}

In the period of March-August 2019, 201 patients were hospitalized with a diagnosis of TB, while in the same period of 2020 only 115 patients, with a case reduction of $43 \%$ Figure 1 shows the number of TB cases by month of hospitalization, both in 2019 and 2020. We observed lower cases during the months of March and April 2020 compared with the same months of 2019; this difference tended to reduce in the months of May, June, and July, and then seemed to increase again during the month of August. The population characteristics of two periods of study are reported in Table 1. During the period included in 2020 more patients with a low BMI were observed, compared to 2019 (57\% vs. 34\% $p<0.01)$; patients were more unemployed, $63 \%$ vs. $46 \%$ ( $p=0.013)$; less instructed $(92 \%$ with $<8$ years of education, vs. $44 \%$ : $p=0.038)$; more smokers, $56 \%$ vs. $35 \%(p<0.01)$. Four TB patients were also coinfected with SARS-CoV-2.

The clinical characteristics are shown in Table 2. During 2020 vs. 2019 period patients with dyspnea ( $23 \%$ vs. $8 \%)$, weight loss $(46 \%$ vs. $28 \%)$, with acute respiratory failure ( $30 \%$ vs. $8 \%$ ) and concurrent extra pulmonary TB (32\% vs. $15 \%)$, were significantly more frequently hospitalized.

Timika score showed a significant worse radiographic pattern in 2020 patients vs. the 2019 group. $(p=<0.01)$.

\subsection{Diagnostic Delays}

A significant increase in total diagnostic delay (TD, time interval between the onset of symptoms and start of TB treatment) was observed. The median patient delay (PD, period from the onset of the first symptom(s) related to pulmonary TB to the first medical 
consultation) was 75 days (IQR: 40-100) in 2020 compared to 30 days (IQR: 10-60) in $2019(p<0.01)$. The delay by month of admission in 2020 was higher for all the months considered, except for March, compared with the same months of 2019 (Figure 2). The healthcare system (HSD, the time interval between the first medical consultation and start of TB treatment) delay was 5 days (IQR: 3-14) in 2020 versus 4 (IQR: 2-10) in 2019; the total delay (PD+HSD) was 90 days (IQR: 58-107) and 38 (IQR: 22-69), in 2020 and in 2019, respectively $(p<0.01)$ (Table 3).

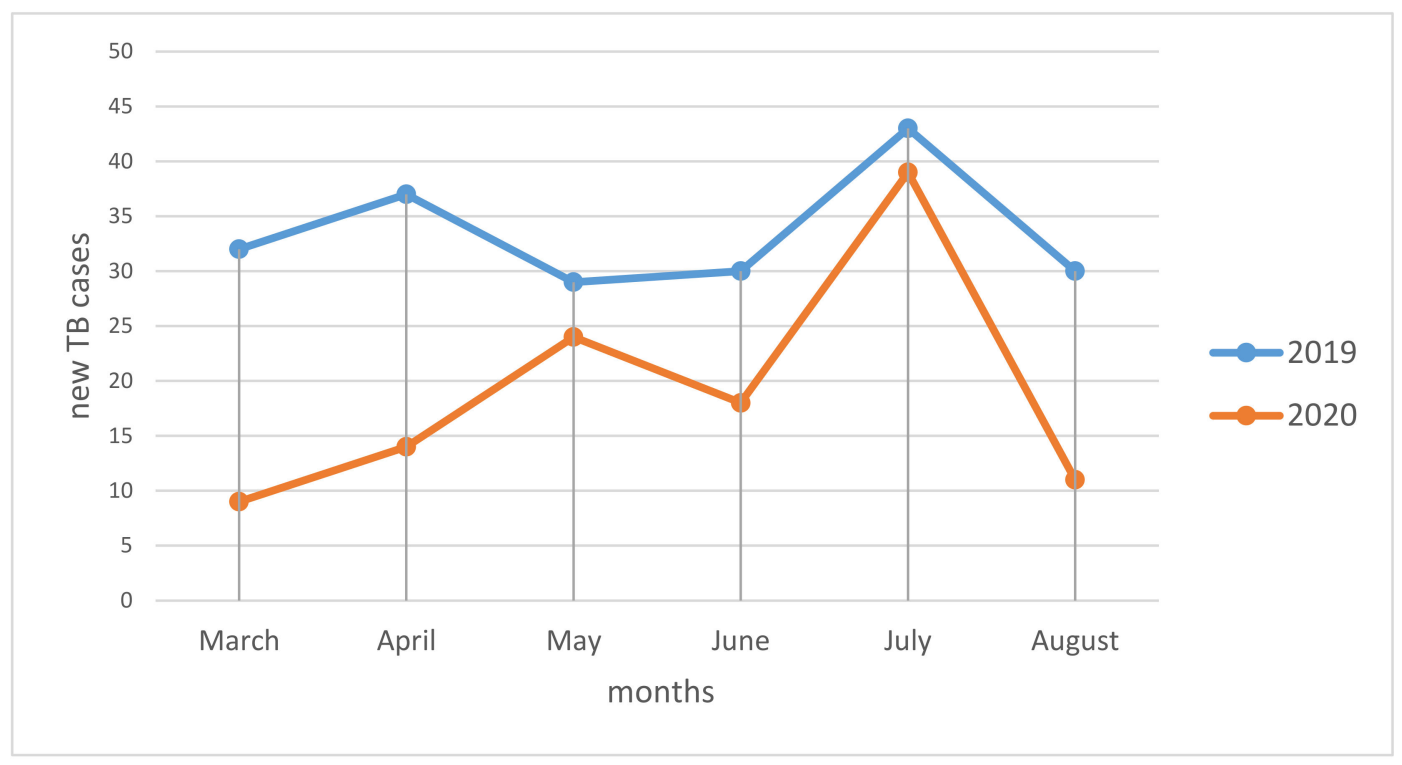

Figure 1. TB cases March August 2019-2020.

Table 1. Population characteristics.

\begin{tabular}{|c|c|c|c|c|}
\hline & & $2020($ tot 115$)$ & 2019 (tot 201) & $p$-Value \\
\hline & & $n(\%)$ & $n(\%)$ & \\
\hline \multirow{2}{*}{ Sex } & Female & $39(34)$ & $59(29)$ & \multirow{2}{*}{0.449} \\
\hline & Male & $76(66)$ & $142(71)$ & \\
\hline \multirow{4}{*}{ BMI } & Low $(16-18,49)$ & $66(57)$ & $68(34)$ & \multirow{4}{*}{$<0.01$} \\
\hline & Normal $(18.5-24,99)$ & $39(34)$ & $121(60)$ & \\
\hline & High $(25-29,99)$ & $10(9)$ & $12(5.5)$ & \\
\hline & Very high (>29.99) & $5(4)$ & $1(0.5)$ & \\
\hline \multirow[t]{3}{*}{ Marital Status } & Single & $50(43)$ & $72(36)$ & \multirow{3}{*}{$<0.01$} \\
\hline & Married & $60(52)$ & $91(45)$ & \\
\hline & Not declared & $5(4)$ & $38(19)$ & \\
\hline \multirow[t]{4}{*}{ Age } & $18-40$ & $41(36)$ & $78(39)$ & \multirow{4}{*}{0.709} \\
\hline & $41-64$ & $60(52)$ & $95(47)$ & \\
\hline & $>65$ & $14(12)$ & $28(14)$ & \\
\hline & Employed & $33(29)$ & $89(44)$ & \\
\hline \multirow[t]{2}{*}{ Occupational status } & Unemployed & $72(63)$ & $92(46)$ & \multirow[t]{2}{*}{0.013} \\
\hline & Retired & $10(9)$ & $20(10)$ & \\
\hline \multirow{3}{*}{ Education } & $<8$ years & $106(92)$ & $168(84)$ & \multirow{3}{*}{0.038} \\
\hline & $>8$ years & $9(8)$ & $33(16)$ & \\
\hline & African & $15(13)$ & $29(14)$ & \\
\hline \multirow{4}{*}{ Nationality } & Central-Sud American & $9(8)$ & $18(9)$ & \multirow{4}{*}{0.99} \\
\hline & Asian & $18(16)$ & $32(16)$ & \\
\hline & East European & $35(30)$ & $60(30)$ & \\
\hline & Italian & $38(33)$ & $62(31)$ & \\
\hline Smoking & Yes & $64(56)$ & $70(35)$ & $<0.01$ \\
\hline
\end{tabular}


Table 2. Clinical characteristics.

\begin{tabular}{|c|c|c|c|c|}
\hline & & $2020($ tot 115$)$ & 2019 (tot 201) & $p$-Value \\
\hline & & $n(\%)$ & $n(\%)$ & \\
\hline Comorbidity & Yes & $63(56)$ & $94(47)$ & 0.160 \\
\hline \multirow[t]{2}{*}{ Previous TB } & Yes & $16(14)$ & $24(12)$ & 0.603 \\
\hline & Diabetes & $14(12)$ & $20(10)$ & 0.574 \\
\hline \multirow{4}{*}{ Risk factor for $\mathrm{TB}$} & Hypertension & $16(14)$ & $27(13)$ & 1.000 \\
\hline & Renal failure & $5(4)$ & $13(6)$ & 0.615 \\
\hline & HIV positive & $5(4)$ & $3(1)$ & 0.145 \\
\hline & Cough & $81(70)$ & $130(65)$ & 0.322 \\
\hline \multirow{5}{*}{ Initial TB symptoms } & Fever & $27(23)$ & $66(33)$ & 0.095 \\
\hline & Dispnea & $26(23)$ & $17(8)$ & $<0.01$ \\
\hline & Night sweats & $27(23)$ & $31(15)$ & 0.096 \\
\hline & Hemoptysis & $11(10)$ & $30(15)$ & 0.223 \\
\hline & Weight loss & $53(46)$ & $56(28)$ & $<0.01$ \\
\hline \multirow{2}{*}{ TB cases } & Bacteriologically confirmed & $94(82)$ & $163(81)$ & \multirow{2}{*}{1.000} \\
\hline & Clinically diagnosed & $21(18)$ & $38(19)$ & \\
\hline \multirow{3}{*}{ Timika score } & Timika $1(\leq 60)$ & $45(39)$ & $134(67)$ & \multirow{3}{*}{$<0.01$} \\
\hline & Timika $2(>60 ; \leq 100)$ & $51(44)$ & $57(28)$ & \\
\hline & Timika $3(>100)$ & $19(17)$ & $10(5)$ & \\
\hline Sputum smear & Positive & $55(48)$ & $82(41)$ & 0.240 \\
\hline \multirow[t]{2}{*}{ Acute respiratory failure } & Yes & $34(30)$ & $17(8)$ & $<0.01$ \\
\hline & Susceptible & $94(82)$ & $176(88)$ & 0.185 \\
\hline \multirow{3}{*}{ Drug resistance } & Monoresistance & $10(9)$ & $12(6)$ & 0.036 \\
\hline & Polydrug resistance & $1(1)$ & $2(1)$ & 1.000 \\
\hline & Multidrug resistance & $9(7)$ & $6(3)$ & 0.059 \\
\hline Concurrent extrapulmonary TB & Yes & $37(32)$ & $31(15)$ & $<0.01$ \\
\hline
\end{tabular}

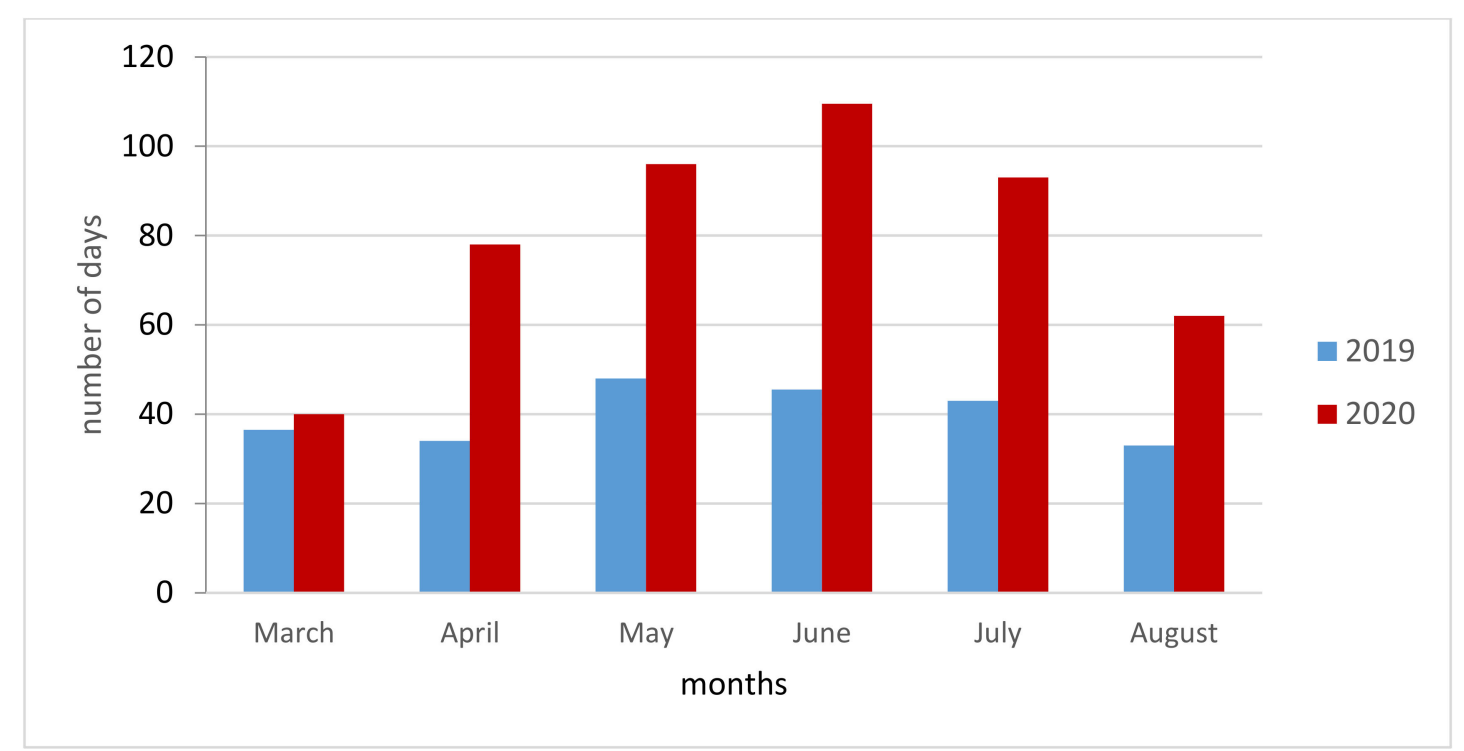

Figure 2. Monthly comparison of Total delay 2019 vs. 2020.

Table 3. Diagnostic delay.

\begin{tabular}{cccc}
\hline & $\mathbf{2 0 2 0}($ tot 115) & 2019 (tot 201) & $p$-Value \\
\hline Patient delay, days (median; IQR) & $\boldsymbol{n} \mathbf{( \% )}$ & $\boldsymbol{n} \mathbf{( \% )}$ & \\
HS, days (median; IQR) & $75(40-100)$ & $30(10-60)$ & $<0.01$ \\
Total, days (median; IQR) & $5(3-14)$ & $4(2-10)$ & 0.032 \\
\hline
\end{tabular}


As Table 4 shown low education ( $<8$ years), foreign nationality, year 2020, BMI $<18.5$, and acute respiratory failure, were found to be linked with long PD.

Table 4. Patients with a patient delay (PD) $>30$ days, stratified by several patient characteristics.

\begin{tabular}{|c|c|c|c|c|c|}
\hline & & \multicolumn{2}{|c|}{ PD > 30 Days } & \multirow[b]{2}{*}{ Total } & \multirow[b]{2}{*}{$p$-Value } \\
\hline & & $\mathbf{N}$ & $\%$ & & \\
\hline \multirow[t]{2}{*}{ Sex } & Male & 118 & 54.1 & 218 & 0.807 \\
\hline & Female & 55 & 56.1 & 98 & \\
\hline \multirow[t]{3}{*}{ Marital status } & Single & 72 & 59 & 122 & 0.084 \\
\hline & Married & 84 & 55.6 & 151 & \\
\hline & Not indicated & 17 & 39.5 & 43 & \\
\hline \multirow[t]{3}{*}{ Age class } & $18-40$ & 66 & 55.5 & 118 & 0.987 \\
\hline & $41-64$ & 84 & 54.2 & 155 & \\
\hline & $>65$ & 23 & 54.8 & 42 & \\
\hline \multirow[t]{2}{*}{ Education } & $<8$ years & 159 & 58 & 274 & 0.004 \\
\hline & $>8$ years & 14 & 33.3 & 42 & \\
\hline \multirow[t]{2}{*}{ Nationality } & Italian & 43 & 43 & 100 & 0.005 \\
\hline & Foreign & 130 & 60.2 & 216 & \\
\hline \multirow[t]{3}{*}{ Occupational status } & Employed & 66 & 54.1 & 122 & 0.957 \\
\hline & Unemployed & 91 & 55.5 & 164 & \\
\hline & Retired & 16 & 55.3 & 30 & \\
\hline \multirow[t]{2}{*}{ Smoke habit } & Yes & 72 & 53.7 & 134 & 0.819 \\
\hline & No & 101 & 55.5 & 182 & \\
\hline \multirow[t]{2}{*}{ Year } & 2020 & 93 & 80.9 & 115 & $<0.01$ \\
\hline & 2019 & 80 & 39.8 & 201 & \\
\hline \multirow[t]{2}{*}{ BMI } & $<18.5$ & 88 & 65.7 & 134 & $<0.01$ \\
\hline & $\geq 18.5$ & 85 & 46.7 & 182 & \\
\hline \multirow[t]{2}{*}{ Comorbidity } & Yes & 94 & 59.5 & 158 & 0.113 \\
\hline & No & 79 & 50 & 158 & \\
\hline \multirow[t]{2}{*}{ Diabetes } & Yes & 20 & 58.8 & 34 & 0.716 \\
\hline & No & 153 & 54.3 & 282 & \\
\hline \multirow[t]{2}{*}{ Hypertension } & Yes & 23 & 53.5 & 43 & 0.871 \\
\hline & No & 150 & 55 & 273 & \\
\hline \multirow[t]{2}{*}{ Renal failure } & Yes & 6 & 33.3 & 18 & 0.086 \\
\hline & No & 167 & 56 & 298 & \\
\hline \multirow[t]{2}{*}{ HIV positive } & Yes & 6 & 75 & 8 & 0.301 \\
\hline & No & 167 & 54.2 & 308 & \\
\hline \multirow[t]{2}{*}{ Acute respiratory failure } & Yes & 38 & 74.5 & 51 & 0.002 \\
\hline & No & 155 & 50.9 & 265 & \\
\hline \multirow[t]{2}{*}{ Previous TB } & Yes & 22 & 55 & 40 & 1.000 \\
\hline & No & 151 & 54.7 & 276 & \\
\hline
\end{tabular}

As shown in Table 5, diagnostic delay in 2020 remain significant in the multiple logistic model (AOR $=6.93,95 \% \mathrm{CI}$ : 3.91-12.30) also when adjusted for gender, education $>8$ years, foreign nationality, occupational status, BMI, the presence of comorbidity, and TB risk factors

Table 5. Association of some characteristics with a patient delay (PD) $>30$ days.

\begin{tabular}{|c|c|c|c|c|c|c|c|}
\hline & & OR & $p$-Value & $95 \%$ CI & AOR & $p$-Value & $95 \% \mathrm{CI}$ \\
\hline \multirow[t]{2}{*}{ Sex } & Male & 0.92 & 0.742 & $(0.57-1.49)$ & NI & & \\
\hline & Female & 1.00 & & & & & \\
\hline \multirow[t]{3}{*}{ Marital status } & Single & 1.14 & 0.574 & $(0.71-1.86)$ & NI & & \\
\hline & Married & 1.00 & & & & & \\
\hline & Not indicated & 0.52 & 0.065 & $(0.26-1.04)$ & & & \\
\hline \multirow[t]{3}{*}{ Age class } & $18-40$ & 1.00 & & & NI & & \\
\hline & $41-64$ & 0.95 & 0.834 & $(0.59-1.54)$ & & & \\
\hline & $>65$ & 0.97 & 0.937 & $(0.48-1.97)$ & & & \\
\hline
\end{tabular}


Table 5. Cont.

\begin{tabular}{|c|c|c|c|c|c|c|c|c|}
\hline & & OR & $p$-Value & $95 \% \mathrm{CI}$ & AOR & $p$-Value & \multicolumn{2}{|c|}{$95 \% \mathrm{CI}$} \\
\hline \multirow[t]{2}{*}{ Education } & $<8$ years & 1.00 & & & NI & & & \\
\hline & $>8$ years & 0.36 & 0.004 & $(0.18-0.72)$ & & & & \\
\hline \multirow[t]{2}{*}{ Nationality } & Italian & 1.00 & & & 1.00 & & & \\
\hline & Foreign & 2.00 & 0.005 & $(1.24-3.24)$ & 2.93 & 0.000 & 1.65 & 5.21 \\
\hline \multirow[t]{3}{*}{ Occupational status } & Employed & 1.00 & & & NI & & & \\
\hline & Unemployed & 1.06 & 0.815 & $(0.66-1.69)$ & & & & \\
\hline & Retired & 0.97 & 0.940 & $(0.44-2.16)$ & & & & \\
\hline \multirow[t]{2}{*}{ Smoke habit } & Yes & 0.93 & 0.756 & $(0.59-1.46)$ & NI & & & \\
\hline & No & 1.00 & & & & & & \\
\hline \multirow[t]{2}{*}{ Year } & 2020 & 6.39 & 0.000 & $(3.71-11.01)$ & 6.93 & 0.000 & 3.91 & 12.30 \\
\hline & 2019 & 1.00 & & & & & & \\
\hline \multirow[t]{2}{*}{ BMI } & $<18.5$ & 2.18 & 0.001 & $(1.38-3.46)$ & NI & & & \\
\hline & $\geq 18.5$ & 1.00 & & & & & & \\
\hline \multirow[t]{2}{*}{ Comorbidity } & Yes & 1.47 & 0.091 & $(0.94-2.29)$ & 2.05 & 0.010 & 1.19 & 3.53 \\
\hline & No & 1.00 & & & & & & \\
\hline \multirow[t]{2}{*}{ Diabetes } & Yes & 1.20 & 0.614 & $(0.59-2.48)$ & NI & & & \\
\hline & No & 1.00 & & & & & & \\
\hline \multirow[t]{2}{*}{ Hypertension } & Yes & 0.94 & 0.858 & $(0.49-1.80)$ & NI & & & \\
\hline & No & 1.00 & & & & & & \\
\hline \multirow[t]{2}{*}{ Renal failure } & Yes & 0.39 & 0.068 & $(0.14-1.07)$ & 0.32 & 0.048 & 0.11 & 0.99 \\
\hline & No & 1.00 & & & & & & \\
\hline \multirow[t]{2}{*}{ HIV positive } & Yes & 2.53 & 0.260 & $(0.50-12.75)$ & NI & & & \\
\hline & No & 1.00 & & & & & & \\
\hline \multirow[t]{2}{*}{ Acute respiratory failure } & Yes & 2.81 & 0.003 & $(1.43-5.52)$ & NI & & & \\
\hline & No & 1.00 & & & & & & \\
\hline \multirow[t]{2}{*}{ Previous TB } & Yes & 1.01 & 0.973 & $(0.52-1.97)$ & NI & & & \\
\hline & No & 1.00 & & & & & & \\
\hline
\end{tabular}

NI: not included.

\section{Discussion}

In this retrospective study, we evaluated socio-economic aspects, clinical, microbiological, and radiological findings of TB patients admitted during two different periods (2019 vs. 2020) to INMI. Our data showed a reduction of hospitalization for TB, with a significative increase of both total and patients delay during 2020 period vs. 2019. In addition, a trend towards greater severity of clinical presentations was observed in 2020. Evaluating hospitalization for TB in our hospital over the period March-August 2020 with the previous year, a significative reduction in hospitalizations-up to $40 \%$-emerged. This evidence is consistent with data form other Italian [15-17] and regional hospital that have confirmed on a large regional scale the reduction in TB cases in 2020 vs. 2019 (Department of Epidemiology of Lazio Regional Health Service, unpublished data). Also, from the experience of other epidemics, there are possible explanations [10-19]. The reorganization of hospital/health services under pressure from COVID-19 resulting in the conversion of tuberculosis wards in COVID-19 unit-had a major indirect impact on the path of care of TB patients, explaining the observed reduction in hospitalization. People with acute and chronic conditions or mild symptoms may have been discouraged from seeking care to reduce crowding in health facilities or fear of getting infected with SARS-CoV-2 in hospital. In addition, the reallocation of healthcare workers and the shift of TB units into COVID-19 units for the pandemic response had an effect in the reduction of health facilities able to diagnosis and treat TB $[20,21]$. As advised by WHO in TB report 2020 [8], there is a risk that the low notification rate of $\mathrm{TB}$ observed, does not means a decrease of incidence but may represents an under-diagnosis likely related to disruption of TB care during first wave of the COVID-19 pandemic. Furthermore, we observed an important and worrying increase of diagnostic delay. In fact, if while in 2019 the time between first symptoms and the start of TB treatment was in average of 38 days, in 2020 this timeframe increased up to a median 
of 90 days. Noteworthy a previous regional survey indicated 78 days in TB total diagnostic delay [22].

We believe that this increasing is strongly related to the SARS-CoV2 pandemic, the consequent lockdown and health system reorganization due to the high burden of cases of SARS-CoV-2 infection. This is in line with other experiences in the literature documenting an increase in diagnostic delay even for non-communicable diseases [23-25]. Comparing the diagnostic delays by each month between 2019 and 2020 (Figure 1), it is possible to highlight that the timeframe between April and July 2020 during lockdown and immediately after was the most critical, while a partial reduction was observed towards August. Diagnostic delays may produce an increase of severity of clinical presentations [26,27]. Indeed, patients diagnosed in 2020 had more severe clinical and radiological findings. They have a higher Timika score, more involved lung lobes and a concomitant diagnosis of extrapulmonary TB. Furthermore, 30\% of 2020 patients showed an acute respiratory failure. TB patients in 2020 had lower education level and were more frequently unemployed people vs. 2019. During COVID-19 pandemic there has been a continued contraction of national economies with income reductions. This could have an impact both in the short but especially in the long term on the population that are already fragile and are more susceptible to TB [28].

In multivariate analysis, differences in TB diagnostic delay times between 2019 and 2020 were strengthened with a 7-fold higher risk for diagnostic delay documented in 2020, but the same behavior was not observed for clinical severity at diagnosis. Although the limited number of patients in our study or the length of the observation time impose caution in interpreting these findings, we think that alarm should be raised in rising the awareness of the high cost of diagnostic delay in terms of outcome and patients' survival. This has been confirmed by several studies [29-31] documenting unfavorable outcomes related to advanced stages of the disease at diagnosis, underlined the pivot role that early symptoms recognition, rapid diagnosis and so early treatment have for TB outcome. The year 2020 is also associated with a higher risk of diagnostic delay in a multivariate model that also included education, gender, foreign nationality, occupational status, BMI, presence of comorbidity and TB risk factors. Furthermore, nine out of 115 patients in 2020 also had SARS CoV2 infection. It cannot be excluded that in these patients, SARS-CoV-2 made the clinical status more severe but also hid the tuberculous signs with an increase in diagnostic delay. For this reason, screening for SARS-CoV-2 during the pandemic is recommended in all patients with TB. In addition, we observed an increase in mortality, with one death in 2019 and three deaths in 2020. These data on outcome, although provisional, are a wake-up call for us to consider.

We recognize some limitations in our study: the enrolment of patients diagnosed in one Institution may limit the extent to which our findings can be generalized. The retrospective nature of the study, the lack of data on LTBI, the need to extend the period of evaluation and the continuous evolution of the COVID-19 pandemic with first wave and second wave can precluded the consideration of other factors potentially influencing diagnostic delay and reduction in hospitalizations.

\section{Materials and Methods}

\subsection{Study Design and Participants}

A retrospective data collection and evaluation was conducted to include all the patients hospitalized for TB at INMI from 9 March to 31 August 2020 (lockdown period and three months thereafter). For the purpose of the study data from patients hospitalized in the same period of 2019 were also collected. Data have been extracted from the local TB database approved by L. Spallanzani Institute Ethics Committee (Decision No. 12/2015). All patients provided written informed consent to the utilization of anonymized clinical data. The inclusion criteria were as follows: diagnosis of tuberculosis according to WHO guidelines, age above 18 years [32]. Data collection included patient's socio-demographic characteristics (i.e., sex, marital status, age, occupational status, education, nationality), risk 
factors for TB (diabetes, chronic renal failure, malignances, being under immunosuppressive therapy, diabetes, renal failure, HIV infection, previous TB and smoking habit), clinical and microbiological characteristics (symptoms, BMI, drug resistance pattern, concurrent extrapulmonary $\mathrm{TB}$, functional respiratory impairment).

As comorbidities, COPD/bronchiectasis, cardiopathy, hypertension, hypothyroidism, dementia, hematological disease, and chronic liver disease were included. Moreover, data on severity were collected at the admission, by the Timika radiographic score [33,34].

We also evaluated total diagnostic delay (TD) as the time interval between the onset of symptoms and start of TB treatment. This included patient delay (PD) and health system delay (HSD); PD: period from the onset of the first symptom(s) related to pulmonary TB to the first medical consultation; HSD: the time interval between the first medical consultation and start of TB treatment $[35,36]$.

\subsection{Statistical Analysis}

Data were summarized using counts and percentage for categorical variables; and with medians and interquartile ranges were utilized for continuous variables. The data were also stratified by calendar period (2019 vs. 2020) and differences between the two periods were assessed using Mann-Whitney test for continuous measures and the Fisher's exact test for categorical data.

A preliminary analysis on the HSD comparing the two periods found that there was, on average, an increase of 1 day. Although this increase was statistically significant, we did not consider this delay as clinically significant; we, thus, evaluated only characteristics potentially associated with a long $\mathrm{PD},(>30$ days) [36], using logistic regression models both univariate and multivariate, with backward selection $(p=0.20)$. The data were analyzed using Stata software, release 15.0. (Stata Corp, College Station, TX, USA).

\section{Conclusions}

In conclusion, our experience suggests that the COVID-19 pandemic has had an impact on TB patient care in terms of higher diagnostic delay, reduced hospitalization, and increased severity of clinical presentations. It is possible that this is the consequence of COVID-19 pandemic and the disruption of TB care services. It should be emphasized that diagnostic delays may produce an increase of $M$. tuberculosis' transmission. The greater effects of COVID-19 pandemic are not yet all visible; therefore, rigorous monitoring involving all national TB center should be perform in order to quantify and prevent them. What is more important to remember is the world will possibly have other pandemics. The priority for all public health is to improve health system resilience to cope with shock events and to be able maintain during crisis the most critical services, including TB one in order to avoid loss of advances in TB control over the past 10 years. Furthermore, a future use of telehealth services can have a pivotal role to guarantee the continuity of care and TB services during a future pandemic.

Author Contributions: Conceptualization, F.P., G.G., F.D.G.; methodology, L.T., G.I.; formal analysis, L.T., F.D.G.; data curation, S.M., P.V., R.L., C.C., L.P., C.N., S.I., N.B., F.I., A.M., S.T., D.G.; writingoriginal draft preparation, F.D.G., G.G., F.P., E.G., L.T.; writing—review and editing, G.I., E.G., F.P.; supervision, F.V., G.I.; Resources, V.D.B. All authors have read and agreed to the published version of the manuscript.

Funding: Our source of found is the Italian Ministry of Health, grant Ricerca Corrente, Research programme n.4: tuberculosis.

Institutional Review Board Statement: The study protocol was approved by L. Spallanzani Institute Ethics Committee (Decision No. 12/2020).

Informed Consent Statement: Informed consent was obtained from all subjects involved in the study. 
Acknowledgments: The authors thank all the physicians, nursing staff and socio-health operators of National Institute for Infectious Diseases "L. Spallanzani", Rome who worked hard during COVID-19 pandemic. Furthermore authors thank the Department of Epidemiology of the Regional Health Service-Lazio.

Conflicts of Interest: The authors declare no conflict of interest.

\section{References}

1. McCloskey, B.; Zumla, A.; Ippolito, G.; Blumberg, L.; Arbon, P.; Cicero, A.; Endericks, T.; Lim, P.L.; Borodina, M. WHO Novel Coronavirus-19 Mass Gatherings Expert Group. Mass gathering events and reducing further global spread of COVID 19: A political and public health dilemma. Lancet 2020, 395, 1096-1099. [CrossRef]

2. Kontis, V.; Bennett, J.E.; Rashid, T.; Parks, R.M.; Pearson-Stuttard, J.; Guillot, M.; Asaria, P.; Zhou, B.; Battaglini, M.; Corsetti, G.; et al. Magnitude, demographics and dynamics of the effect of the first wave of the COVID-19 pandemic on all-cause mortality in 21 industrialized countries. Nat. Med. 2020, 26, 1919-1928. [CrossRef] [PubMed]

3. Alfano, V.; Ercolano, S. The Efficacy of Lockdown Against COVID-19: A Cross-Country Panel Analysis. Appl. Health Econ. Health Policy 2020, 18, 509-517. [CrossRef]

4. World Health Organization (WHO). The Impact of the COVID-19 Pandemic on Noncommunicable Disease Resources and Services: Results of a Rapid Assessment; WHO: Geneva, Switzerland, 2020; Available online: https:/ / www.who.int/teams/noncommunicablediseases / covid-19 (accessed on 10 February 2021).

5. Maringe, C.; Spicer, J.; Morris, M.; Purushotham, A.; Nolte, E.; Sullivan, R.; Rachet, B.; Aggarwal, A. The impact of the COVID-19 pandemic on cancer deaths due to delays in diagnosis in England, UK: A national, population-based, modelling study. Lancet Oncol. 2020, 21, 1023-1034. [CrossRef]

6. Cilloni, L.; Fu, H.; Vesga, J.F.; Dowdy, D.; Pretorius, C.; Ahmedov, S.; Nair, S.A.; Mosneaga, A.; Masini, E.; Sahu, S.; et al. The potential impact of the COVID-19 pandemic on the tuberculosis epidemic a modelling analysis. EClinicalMedicine 2020, $28,100603$. [CrossRef]

7. McQuaid, C.F.; McCreesh, N.; Read, J.M.; Sumner, T.; CMMID COVID-19 Working Group. The potential impact of COVID-19related disruption on tuberculosis burden. Eur. Respir. J. 2020, 56, 2001718. [CrossRef]

8. World Health Organization (WHO). Global Tuberculosis Report; WHO: Geneva, Switzerland, 2020; Available online: https: / /www.who.int/publications/i/item/9789240013131 (accessed on 7 February 2021).

9. Barrett, J.; Painter, H.; Rajgopal, A.; Keane, D.; John, L.; Papineni, P.; Whittington, A. Increase in disseminated TB during the COVID-19 pandemic. Int. J. Tuberc. Lung Dis. 2021, 25, 160-166. [CrossRef] [PubMed]

10. Bhatia, V.; Mandal, P.P.; Satyanarayana, S.; Aditama, T.Y.; Sharma, M. Mitigating the impact of the COVID-19 pandemic on progress towards ending tuberculosis in the WHO South-East Asia Region WHO South East Asia. J. Public Health 2020, 9, 95-99. [CrossRef] [PubMed]

11. Migliori, G.B.; Thong, P.M.; Akkerman, O.; Alffenaar, J.-W.; Álvarez-Navascués, F.; Assao-Neino, M.M.; Bernard, P.V.; Biala, J.S.; Blanc, F.-X.; Bogorodskaya, E.M.; et al. Worldwide Effects of Coronavirus Disease Pandemic on Tuberculosis Services, January-April 2020. Emerg. Infect. Dis. 2020, 26, 2709-2712. [CrossRef] [PubMed]

12. Italian National Health Institute (Istituto Superiore di Sanità). Coronavirus Epidemic: Situation Report. 9 March 2020. Available online: https:/ / www.epicentro.iss.it/coronavirus/bollettino/Bollettino-sorveglianza-integrata-COVID-19_9-marzo\%202020.pdf (accessed on 6 February 2021).

13. Gazzetta Ufficiale. Available online: https://www.gazzettaufficiale.it/eli/id/2020/03/09/20A01558/sg (accessed on 2 February 2021).

14. Berardi, C.; Antonini, M.; Genie, M.G.; Cotugno, G.; Lanteri, A.; Melia, A.; Paolucci, F. The COVID-19 pandemic in Italy: Policy and technology impact on health and non-health outcomes. Health Policy Technol. 2020, 9, 454-487. [CrossRef] [PubMed]

15. Magro, P.; Formenti, B.; Marchese, V.; Gulletta, M.; Tomasoni, L.R.; Caligaris, S.; Castelli, F.; Matteelli, A. Impact of the SARS-CoV-2 epidemic on tuberculosis treatment outcome in Northern Italy. Eur. Respir. J. 2020, 56, 2002665. [CrossRef] [PubMed]

16. Fonseca, G.A.; Normando, P.G.; Loureiro, L.V.M.; Oliveira, V.A.; Melo, M.D.T.; Santana, I.A. Reduction in the Number of Procedures and Hospitalizations and Increase in Cancer Mortality During the COVID-19 Pandemic in Brazil. JCO Glob. Oncol. 2021, 7, 4-9. [CrossRef]

17. De Rosa, S.; Spaccarotella, C.; Basso, C.; Calabrò, M.P.; Curcio, A.; Filardi, P.P.; Mancone, M.; Mercuro, G.; Muscoli, S.; Nodari, S.; et al. Reduction of hospitalizations for myocardial infarction in Italy in the COVID-19 era. Eur. Heart J. 2020, 41, 2083-2088.

18. Zumla, A.; McHugh, B.; Maeurer, M.; Zumla, A.; Kapata, N. COVID-19 and tuberculosis-Threats and opportunities. Int. J. Tuberc. Lung Dis. 2020, 24, 18-25. [CrossRef] [PubMed]

19. Quaglio, G.; Tognon, F.; Finos, L.; Bome, D.; Sesay, S.; Kebbie, A.; Di Gennaro, F.; Camara, B.S.; Marotta, C.; Pisani, V.; et al. Impact of Ebola outbreak on reproductive health services in a rural district of Sierra Leone: A prospective observational study. BMJ Open 2019, 9, e029093. [CrossRef] [PubMed] 
20. Ong, C.W.M.; Migliori, G.B.; Raviglione, M.; MacGregor-Skinner, G.; Sotgiu, G.; Alffenaar, J.W.; Tiberi, S.; Adlhoch, C.; Alonzi, T.; Archuleta, S.; et al. Epidemic and pandemic viral infections: Impact on tuberculosis and the lung: A consensus by the World Association for Infectious Diseases and Immunological Disorders (WAidid), Global Tuberculosis Network (GTN), and members of the European Society of Clinical Microbiology and Infectious Diseases Study Group for Mycobacterial Infections (ESGMYC). Eur Respir J. 2020, 56, 2001727. [CrossRef]

21. Louie, J.K.; Reid, M.; Stella, J.; Agraz-Lara, R.; Graves, S.; Chen, L.; Hopewell, P. A decrease in tuberculosis evaluations and diagnoses during the COVID-19 pandemic. Int. J. Tuberc. Lung Dis. 2020, 24, 860-862. [CrossRef]

22. Pezzotti, P.; Pozzato, S.; Ferroni, E.; Mazzocato, V.; Altieri, A.M.; Gualano, G.; Loffredo, M.; Napoli, P.A.; Perrelli, F.; Girardi, E. Delay in diagnosis of pulmonary tuberculosis: A survey in the Lazio region, Italy. Epidemiol. Biostat. Public Health 2015, 12, 1-10.

23. Ferrara, G.; De Vincentiis, L.; Ambrosini-Spaltro, A.; Barbareschi, M.; Bertolini, V.; Contato, E.; Crivelli, F.; Feyles, E.; Mariani, M.P.; Morelli, L.; et al. Cancer Diagnostic Delay in Northern and Central Italy During the 2020 Lockdown Due to the Coronavirus Disease 2019 Pandemic. Am. J. Clin. Pathol. 2021, 155, 64-68. [CrossRef]

24. De Vincentiis, L.; Carr, R.A.; Mariani, M.P.; Ferrara, G. Cancer diagnostic rates during the 2020 "lockdown," due to COVID-19 pandemic, compared with the 2018-2019: An audit study from cellular pathology. J. Clin. Pathol. 2021, 74, 187-189. [CrossRef]

25. D'Ovidio, V.; Lucidi, C.; Bruno, G.; Lisi, D.; Miglioresi, L.; Bazuro, M.E. Impact of COVID-19 Pandemic on Colorectal Cancer Screening Program. Clin. Colorectal Cancer 2020, 1533. [CrossRef]

26. Guthmann, J.-P.; Léon, L.; Antoine, D.; Lévy-Bruhl, D. Tuberculosis treatment outcomes of notified cases: Trends and determinants of potential unfavourable outcome, France, 2008 to 2014. Eurosurveillance 2020, 25, 1900191. [CrossRef]

27. Bojovic, O.; Medenica, M.; Zivkovic, D.; Rakocevic, B.; Trajkovic, G.; Kisic-Tepavcevic, D.; Grgurevic, A. Factors associated with patient and health system delays in diagnosis and treatment of tuberculosis in Montenegro, 2015-2016. PLoS ONE 2018, 13, e0193997. [CrossRef] [PubMed]

28. Di Gennaro, F.; Pizzol, D.; Cebola, B.; Stubbs, B.; Monno, L.; Saracino, A.; Luchini, C.; Solmi, M.; Segafredo, G.; Putoto, G.; et al. Social determinants of therapy failure and multi drug resistance among people with tuberculosis: A review. Tuberculosis 2017, 103, 44-51. [CrossRef]

29. Sreeramareddy, C.T.; Qin, Z.Z.; Satyanarayana, S.; Subbaraman, R.; Pai, M. Delays in diagnosis and treatment of pulmonary tuberculosis in India: A systematic review. Int. J. Tuberc. Lung Dis. 2014, 18, 255-266. [CrossRef]

30. Tattevin, P.; Che, D.; Fraisse, P.; Gatey, C.; Guichard, C.; Antoine, D.; Paty, M.C.; Bouvet, E. Factors associated with patient and health care system delay in the diagnosis of tuberculosis in France. Int. J. Tuberc. Lung Dis. 2012, 16, 510-515. [CrossRef] [PubMed]

31. Di Gennaro, F.; Vittozzi, P.; Gualano, G.; Musso, M.; Mosti, S.; Mencarini, P.; Pareo, C.; Di Caro, A.; Schininà, V.; Girardi, E.; et al. Active Pulmonary Tuberculosis in Elderly Patients: A 2016-2019 Retrospective Analysis from an Italian Referral Hospital. Antibiotics 2020, 9, 489. [CrossRef]

32. World Health Organitation (WHO). Guidelines for Treatment of Drug-Susceptible Tuberculosis and Patient Care; WHO: Geneva, Switzerland, 2017; Available online: https:/ /apps.who.int/iris/bitstream/handle/10665/255052/9789241550000-eng.pdf?sequence=1 (accessed on 1 February 2021).

33. Chakraborthy, A.; Shivananjaiah, A.J.; Ramaswamy, S.; Chikkavenkatappa, N. Chest X ray score (Timika score): An useful adjunct to predict treatment outcome in tuberculosis. Adv. Respir. Med. 2018, 86, 205-210. [CrossRef]

34. Thiel, B.A.; Bark, C.M.; Nakibali, J.G.; Van Der Kuyp, F.; Johnson, J.L. Reader variability and validation of the Timika X-ray score during treatment of pulmonary tuberculosis. Int. J. Tuberc. Lung Dis. 2016, 20, 1358-1363. [CrossRef]

35. World Health Organization (WHO). Diagnostic and Treatment Delay in Tubercolosis. WHO Regional Office Eastern Mediterranean; WHO: Geneva, Switzerland, 2006; Available online: https:/ /apps.who.int/iris/handle/10665/116501 (accessed on 2 February 2021).

36. Datiko, D.G.; Jerene, D.; Suarez, P. Patient and health system delay among TB patients in Ethiopia: Nationwide mixed method cross-sectional study. BMC Public Health 2020, 20, 1-10. [CrossRef] 